\title{
International Scientific Conference
}

\section{ENVIRONMENTAL SCIENCE FOR CONSTRUCTION INDUSTRY - ESCI 2018}
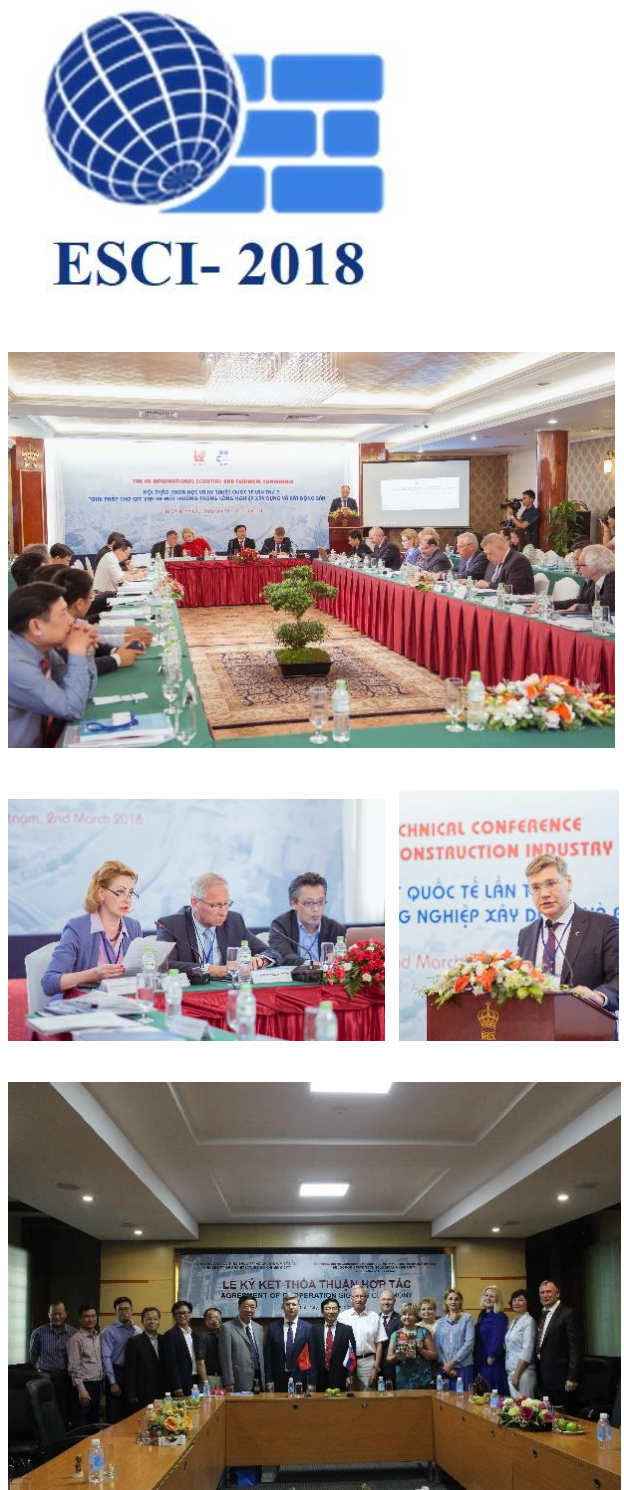

Conference organisers:

- Moscow State University of Civil Engineering (MGSU) Russia

- University of Architecture Ho Chi Minh City (UAH), Vietnam

ESCI 2018 conference took place on 2-5 of March 2018 in Ho Chi Minh City, Vietnam. Moscow State University of Civil Engineering was welcomed by the colleagues from University of Architecture Ho Chi Minh City.

ESCI 2018 attracted scientific community representatives from 12 countries, who presented their works and spoke on the issue of increasing the ecological potential of urban territories and ensuring the ecological safety of the population. The conference provided scientists, environmentalists, architects, builders, economists, and specialists in other areas with a platform to discuss relevant environmental problems arising in the construction sector.

The following topics were in the spotlight of the conference: the management of natural-andanthropogenic systems of the cities, energy conservation, environmental rehabilitation of territories of large cities and risk management in sustainable urban development, providing ecological safety of development of urban complexes and territories of large cities.

The conference was aimed at sharing knowledge on the most important scientific and technological achievements that could help to solve the environmental problems of urban areas. The results can be applied in activities of regional and municipal legislative and executive authorities when making management or organizational and economic decisions on issues of construction and real estate.

Within the conference, several seminars and round tables were held, the participants visited scientific research laboratories and scientific and educational centers. We expect that the results of the conference will make a great contribution to the solution of environmental problems of large cities.

On behalf of all the participants, we express our gratitude to the crew of the MATEC Web of Conferences journal for helping us in preparation and publication of the proceedings of our conference.

\section{We wish your journal well-being and prosperity!}

